\title{
Çoklu Bölmeli Kare Tankta Su Çalkalanmasının Sayısal Araştırması
}

\author{
Ferhat Koca $^{1 *}$, Mustafa Zabun ${ }^{2}$ \\ 1* Sivas Cumhuriyet Üniversitesi, Teknoloji Fakültesi, İmalat Mühendisliği Bölümü, Sivas, Türkiye, (ORCID: 0000-0001-8849-5295), ferhatkoca@cumhuriyet.edu.tr \\ ${ }^{2}$ Yeditepe Üniversitesi, Mühendislik Fakültesi, Makine Mühendisliği Bölümü, İstanbul, Türkiye (ORCID: 0000-0003-0420-4134), mzabun@outlook.com
}

(1st International Conference on Applied Engineering and Natural Sciences ICAENS 2021, November 1-3, 2021)

(DOI: 10.31590/ejosat.1012629)

ATIF/REFERENCE: Koca, F., \& Zabun, M. (2021). Çoklu Bölmeli Kare Tankta Su Çalkanmasının Sayısal Araştırması. Avrupa Bilim ve Teknoloji Dergisi, (28), 1062-1070.

$\ddot{O} \mathbf{z}$

Çalkalanma, kısmen doldurulmuş tankların içindeki sıvıların hareketini tanımlar ve tank yapısı üzerinde dinamik yükler oluşturur. Tankın yapısal mukavemetinin değerlendirilmesinde çalkalanma sonucu ortaya çıkan darbe basınçlarının önemi yüksektir. Bu basınçların tespitinin zorluğu tasarımcılar açısından sorun teşkil etmektedir. Bu çalışmada, kare bir tankta yatay hareketlerin çalkantı etkisi hesaplamalı akışkanlar dinamiği (HAD) uygulaması olan ANSYS-FLUENT analiz programı kullanılarak sayısal olarak incelenmiştir. $\% 50$ su dolu kare bir tankın, yan duvarlarına farklı açılarda perdeler $\left(10^{\circ}, 20^{\circ}\right.$ ve $\left.30^{\circ}\right)$ ve zeminine farklı sayılarda perdeler (tek ve çift) yerleştirilmiştir. 0-2 sn. süre arasında tank pozitif, 2-4 sn. süre arasında negatif ve 4-6 sn. süre arasında tekrar pozitif x ekseninde $4.5 \mathrm{~m} / \mathrm{s} 2$ 'lik hız ile hareket ettirilmiştir. Akışkan ara yüzünü yakalamak için VOF metodu kullanılmıştır. Her tank konfigürasyonuna bağlı olarak belirlenen noktalardan dinamik basınç ölçümleri yapılmış ve her tank konfigürasyonu için akışkan ara yüz hareketleri karşılaştırılmıştır. Edinilen veriler yorumlanarak sonuç olarak yazılmıştır.

Anahtar Kelimeler: Çalkalanma, çalkantı, HAD, tank, VOF method.

\section{Numerical Investigation of Water Sloshing in Square Tank with Multiple Baffles}

\begin{abstract}
Sloshing describes the movement of liquids inside partially filled tanks and creates dynamic loads on the tank structure. In the evaluation of the structural strength of the tank, the impact pressures resulting from agitation are of great importance. The fact that the determination of these pressures is not easy poses a problem for the designers. In this study, the sloshing effect of horizontal movements in a square tank was numerically investigated using the ANSYS-FLUENT analysis program, which is a Computational Fluid Dynamics application. A square tank filled with $50 \%$ water has baffles at different angles $\left(10^{\circ}, 20^{\circ}\right.$ and $\left.30^{\circ}\right)$ on the side walls and different numbers of baffles (single and double) on the floor. The tank was moved with a velocity of $4.5 \mathrm{~m} / \mathrm{s} 2$ in the negative $\mathrm{x}$-axis between $0-2$ seconds and in the positive $\mathrm{x}$-axis between 4-6 seconds. The VOF method was used to capture the fluid interface. Dynamic pressure measurements were made from the points determined depending on each tank configuration and fluid interface movements were compared for each tank configuration. The given data has been interpreted and written as a result.
\end{abstract}

Keywords: Sloshing, swash, CFD, tank, VOF method.

\footnotetext{
* Sorumlu Yazar: ferhatkoca@,cumhuriyet.edu.tr
} 


\section{Giriş}

Çalkantı, bir kaptaki sıvının serbest yüzeyinin herhangi bir hareketi olarak tanımlanabilir. Çalkantı tasarım ve ürün geliştirmelerde her zaman büyük bir problem olmuştur. Akışkanın eylemsizlikten dolayı verdiği kaotik tepkiler, çalkantının bilinmezliğinin başlıca nedenidir. Kısmen veya yarı dolu sıvı yüklü tankların maruz kalacağı herhangi bir dış kuvvet, eylemsizlik prensibine bağlı olarak çalkantı hareketine sebep olabilir ve bu da tank yapısında büyük deformasyonlara neden olabilir. Çalkantı, başta deniz taşımacılığı olmak üzere havacılık, uzay ve otomotiv alanlarında sıkça karşılaşılan bir olgudur.

Çalkantı oluşumu temelde tankın yapısına: dikdörtgen, konik, küresel, kare ve silindirik vb. tank içerisinde bulunan sıvının cinsine; petrol ve petrol ürünleri, su, melas gibi birçok etkene bağlıdır. Çalkantının birçok nedenden dolayı oluşması çalkantı analizlerinin karmaşık, tahmin edilmesi zor olduğunun ispatıdır. $\mathrm{Hu}$ vd. (2017) tarafindan belirtildiği gibi deniz taşımacılığında, LNG (Sıvılaştırılmış Doğal Gaz) tanklarının geminin seyir halinde farklı dalga tiplerinde incelemiş ve tank içerisindeki çalkantı etkilerinin üzerinde durmuş ve çalkantı olgusunun önemli etiklerini belirtmiştir. Klatte vd. (2020) membran tankları deneysel olarak incelemiş ve çalkantı etkisinin tank içerisindeki akışkan seviyesine ve toplam kıvrım alanına bağglı olduğunu ispatlamıștır. Rudman ve Cleary (2009), LNG tanklarının farklı dolum seviyelerinde tank duvarının farklı noktalarına yerleştirdiği basınç sensörleri ile tank duvarına gelen basınç değerlerini ölçmüştür. Ölçümler sonucunda tank yüzeyine gelen basıncın tank seviyesine bağlı olarak değiştiğini ispatlamıştır. Ayrıca, çalkantı etkisinin sadece tankı deforme etmediğini geminin seyir halindeyken geminin dengesini etkilediğini öne sürmüş̧ür.

Thiagarjan vd. (2011), çalkalanma uyarımına maruz kalan 2B dikdörtgen bir tankta sıvı çalkalanmasını simüle etmişlerdir. Akışkanın alanını modellemek için sonlu bir hacim yaklaşımı kullanarak, hava-su ara yüzünü izlemek için VOF tekniğini uygulamışlardır. Doldurma seviyelerini ve uyarma süreleri gibi çeşitli parametrelerin sıvı çalkantı dinamikleri üzerindeki etkilerini incelemiş ve sayısal sonuçları literatürdeki mevcut teorik tahminlerle karşılaştırmışlardır. Wang vd. (2013) yanal uyarma yaşayan sert silindirik bir tankta sıvı çalkantısını bastırmak veya hafifletmek için çoklu dairesel sert bölmeler uygulamanın fizibilitesini araştırmışıı. Yazarlar son olarak araştırmalarında, hidrodinamik basınç dağılımı, yüzey dalasının yüksekliği ve hidrodinamik momentum ve bir tankın harmonik ve sismik uyarılar altındaki kuvveti gibi çeşitli parametreleri tartışmışlardır.

Tank tasarlayıcıların hedeflerinden biri de çalkalanmayı kontrol etmektir. Çalkanmanın kontrolü için yaygın kullanılan yöntemlerden birisi tank içerisine perdeler eklenerek çalkanma etkisini azaltmaktır. Hem dikdörtgen hem de silindirik tankların sıvı çalkalanmasını bastırmak için gözenekli ve gözeneksiz perdelerin kullanılabilirliği literatürde birçok araştırmacı tarafından kapsamlı bir şekilde araştırılırken, perdelerin analiz sırasında sabitlenmesi gerekir. Tank içerisine yerleştirilen perdelerin kullanımı ticari anlamda tankın maliyetini arttırmakta, ayrıca tankın ağırlığı da artmaktadır. Dolayısıyla tankın içerisine yerleştirilecek perdelerin konumları, adetleri, yerleştirme yüksekliği ve açıları son derece önem kazanmaktadır. Sanapa vd. (2018) kısmen doldurulmuş dikdörtgen bir tankta siv1 çalkantısının dinamiklerini sayısal simülasyonlar yaparak incelemiştir. Tank, harmonik tipte dikey ve yatay ivmeye ve sismik hareketlere maruz bırakılmıştır. Araştırmacıların çalışması, serbest yüzey hareketlerini ve ayrıca çalkantı kaynaklı kuvvetleri kontrol etmek için perde kullanmanın önemini göstermiştir.

Bu çalışma, Şahin ve Bayraktar'ın (2015) kare bir tank için 2 farklı açılarda perde kullandıkları araştırmalarından esinlenmiştir. $\mathrm{Bu}$ konfigürasyona ek olarak mevcut makalede yeni geometri tanımlanmış ve ANSYS-FLUENT R19 programı aracılığı ile analizleri yapılmıştır. Kısmen dolu tankların sağ ve sol yan duvarlarına sabitlenen 10,20 ve 30 derece y ekseni yönünde açılar verilerek, zeminlerine 2 adet perde eklenmiştir. Tanklar farklı zaman aralıklarında farklı yönlerde uyarımlar yapılarak incelenmiştir. İlk önce $0-2 \mathrm{sn}$. arasında $+x$ yönünde $4.5 \mathrm{~m} / \mathrm{s} 2$ ivmeyle, $2-4 \mathrm{sn}$. arasında $-\mathrm{x}$ yönünde $4.5 \mathrm{~m} / \mathrm{s} 2$ ve son olarak 4-6 sn. arasında $+x$ yönünde $4.5 \mathrm{~m} / \mathrm{s} 2$ olmak üzere toplamda $6 \mathrm{sn}$. olacak şekilde yanal uyarımlar verilerek Ansys-FLUENT programında VOF model kullanılarak analiz edilip sonuçlar karşılaştırılmıştır.

\section{Materyal ve Metot}

\subsection{Model Tanımı}

Kısmen dolu tankta içindeki sıvının hareketinden dolayı çalkalanmanın meydana geldiği bir gerçektir. Pasif bir kontrol yöntemi olarak, perdeler çalkalanmanın ciddi etkilerini azaltmak için kullanılabilir. Așağıdaki örnek olay incelemeleri, bölmelerle ve bölmeler olmadan kısmen doldurulmuş sert tanklarda çalkalanmayı simüle eder ve her konfigürasyon için rapor eder.

\subsubsection{Tank Konfigürasyonu}

$250 \mathrm{~mm} \times 250 \mathrm{~mm}$ ölçülerinde dikdörtgen tank çalkalanma performansı değerlendirmek için Şahin ve Bayraktar'ın yazısından esinlenilerek (2015), zeminde 1 ve 2 perdelerden oluşan ve her perde için yan duvarlardaki yatay perdeler 10,20 ve 30 derece açı verilerek konfigüre edilmiştir. Her tank konfigürasyonunda su seviyesi $\% 50$ olarak hesaba katılmıştır. Tankların ve bölmelerin boyutları Şekil 1 'de gösterilmiştir.
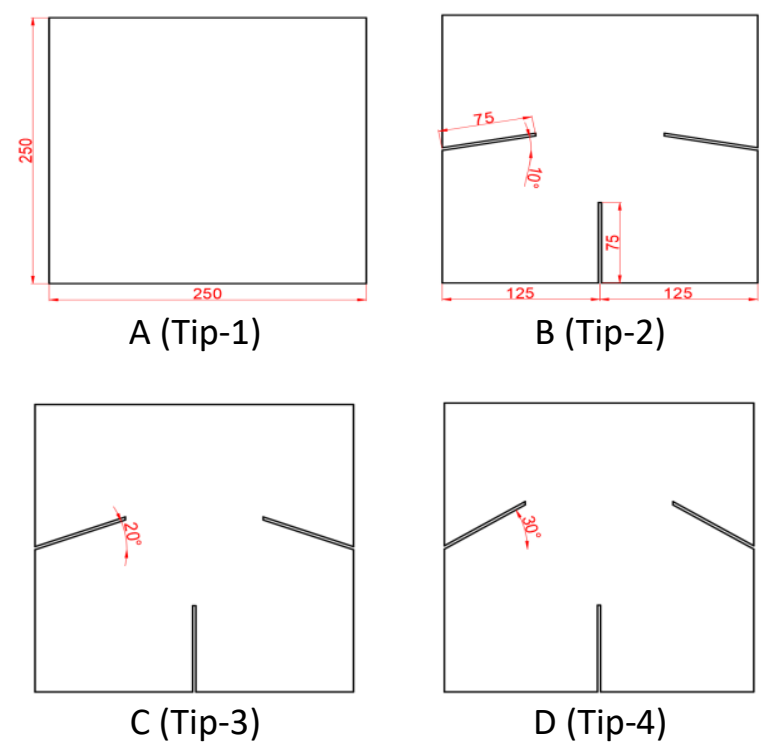

Şekil 1. Zeminde Tek Perdeli Tank Boyutları (mm) 
Şekil 1A'da gösterildiği gibi birinci tankta herhangi bir bölme yoktur, Şekil 1B'de gösterilen tankın yan duvarlarından $10^{\circ}$ açı ile kaldırılmış perdeler bulunmaktadır. Şekil 1C'de perdeler $20^{\circ}$ ve Şekil $1 \mathrm{D}^{`}$ de $30^{\circ}$ kaldırılarak konfigüre edilmiştir.

Şekil 2'de ise Şekil 1'de verilen açılı perdelere ek olarak zeminde yan duvarlara paralel 2 perde kullanılarak konfigüre edilmiştir.

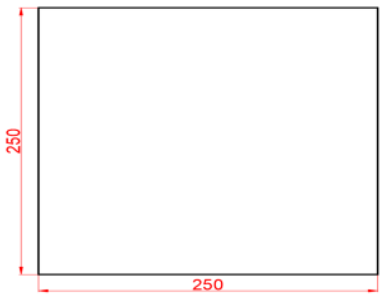

A (Tip-1)

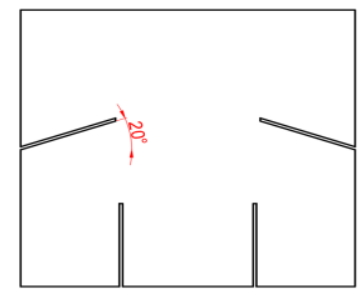

C (Tip-6)

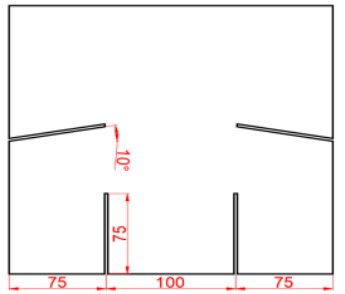

B (Tip-5)

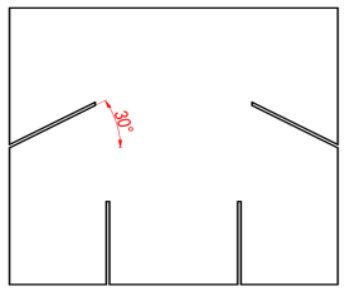

D (Tip-7)
Şekil 2. Zeminde Çift Perdeli Tank Boyutları (mm)

Tüm tank türleri aşağıdaki varsayımlara göre incelenmiştir:

> Tanklar 0-2 sn aralığında $4,5 \mathrm{~m} / \mathrm{s} 2$ hızla $+x$ yönünde hareket etmektedir,

> Tanklar 2-4 sn aralığında $4,5 \mathrm{~m} / \mathrm{s} 2$ hızla ile -x yönünde hareket etmektedir,

> Tanklar 4-6 sn aralığında $4,5 \mathrm{~m} / \mathrm{s} 2$ hızla ile $+\mathrm{x}$ yönünde hareket etmektedir.

\subsubsection{Mesh Yaptst}

Mesh yapısının kalitesini gösteren mesh elemanlarının sayısı, en boy oranları ve çarpıklığı Tablo.1'de özetlenmiştir.

Tablo 1: Tank Yapılarının Mesh Kaliteleri

\begin{tabular}{|c|c|c|c|}
\hline & $\begin{array}{c}\text { Eleman } \\
\text { Sayısı }\end{array}$ & $\begin{array}{c}\text { Maksimum } \\
\text { en-boy oranı }\end{array}$ & $\begin{array}{c}\text { Maksimum } \\
\text { çarpıklık }\end{array}$ \\
\hline Tip 1 & 62484 & 16,119 & 0,57481 \\
\hline Tip 2 & 62256 & 29,543 & 0,64205 \\
\hline Tip 3 & 77025 & 18,823 & 0,51338 \\
\hline Tip 4 & 62635 & 25,301 & 0,61537 \\
\hline Tip 5 & 62155 & 16,885 & 0,54599 \\
\hline Tip 6 & 97058 & 2,575 & 0,58863 \\
\hline Tip 7 & 97687 & 22,492 & 0,58046 \\
\hline
\end{tabular}

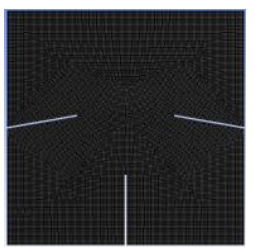

Tip-2

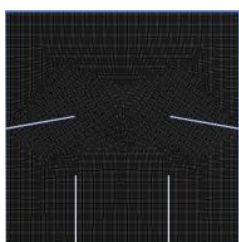

Tip-5

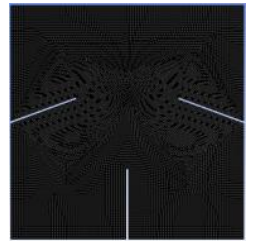

Tip-3

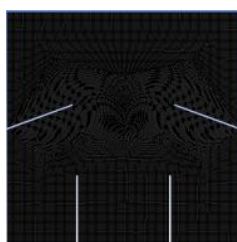

Tip-6

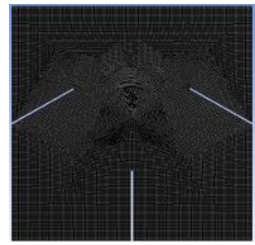

Tip-4

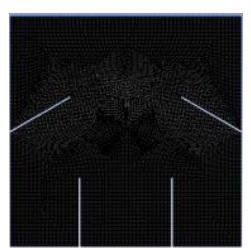

Tip-7
Şekil 3: Tankları Mesh Görünümü

\subsection{Matematik Model}

Çalkantıyı simüle etmek için kullanılan denklemler süreklilik (Denklem 1), Navier-Stokes (Denklem 2) ve VOF denklemleridir. Bunlar genel olarak aşağıdaki şekilde verilmiştir:

$$
\Delta \vec{V}=0
$$

$$
\frac{D \vec{V}}{D t}+\left[-\frac{1}{\rho}(\nabla p-\mu(\vec{\nabla} \vec{\nabla}) \vec{V})\right]+\overrightarrow{F_{B}}
$$

Momentum denklemi, tüm fazların hacim fraksiyonlarına bağlıdır ve Denklem 3 'te verilmiştir.

$$
\frac{\partial u}{\partial t}+(\vec{V} \vec{\nabla}) \vec{V}=-\frac{1}{\rho}(\nabla p-\mu(\vec{\nabla} \vec{\nabla}) \vec{V})+F_{B}+F_{V}
$$

Burada, $\vec{V}$ tanka göre akışkan hızıdır, p basınçtır; $\rho$ sıvı yoğunluğu ve $\mu$ viskozitedir. $F_{B}$ ve $F_{v}$ durumu cisim kuvveti ve tankin hareketinin neden olduğu sanal cisim kuvvetidir. Nema (2014) yayınladığı makalede ayrıntılı olarak belirttiği gibi çeşitli teknikler vardır.

> Hareketli ızgara veya Lagrangian yaklaşımı (yakalama),

$>$ Sabit ızgara veya Euler yaklaşımı (izleme),

$>$ Lagrangian ve Eulerian'ın birleşik yöntemi

$\mathrm{Bu}$ çalışmada Euler yaklaşımının bir parçası VOF kullanılmıştır. VOF modeli, tüm akışkan fazları (burada hava ve su) arasında herhangi bir etkileşim olmadığını varsayar. Her bir kontrol hacmi için, hücredeki fazın hacim fraksiyonu tanıtılacak ve tüm fazların hacim fraksiyonu, birliğe toplanacaktır. $\alpha b$, hücredeki her iki sıvının hacim fraksiyonunu temsil ediyorsa, aşağıdaki üç koşul mümkündür:

$>\alpha_{\mathrm{b}}=0,[$ Hücrenin boş olduğunu gösterir (b tipi sıvı yoktur)]

$>\quad \alpha_{\mathrm{b}}=1,[$ Hücrenin dolu olduğunu gösterir (sadece $\mathrm{b}$ tipi siv1 mevcuttur)] 
$>0<\alpha_{\mathrm{bz}}<1$ [Hücrenin, hem siv1 hem de bir veya daha fazla başka sıvı türü arasındaki ara yüzü içerdiğini gösterir.]

Her iki faz için hacim fraksiyonu (VOF) Denklem 4 'te verilmiştir.

$$
\frac{1}{\rho}\left[\frac{\partial}{\partial t}\left(\alpha_{b} \rho_{b}\right)\right]+\vec{\nabla}\left(\alpha_{b} \rho_{b} \overrightarrow{V_{b}}\right)=s_{\alpha_{b}} \sum\left(\dot{m}_{a b} \dot{m}_{b a}\right)
$$

Burada $\dot{m}_{a b}, \dot{m}_{b a}$ ve $s_{\alpha_{b}}$ a'dan b fazına kütle aktarımı, b'den bir faza kütle aktarımı ve kavitasyon modelinin kullanımına izin veren kaynak terimidir. $\mathrm{n}$ faz için:

$$
\sum_{b=1}^{n} \alpha_{b}=1
$$

Aşağıdaki denklem, a ve b için 2 fazlı akışta fiziksel parametreleri hesaplamak için kullanılır:

$$
\begin{aligned}
& \rho=\alpha \rho_{b}+(1-\alpha) \rho_{a} \\
& \mu=\alpha \mu_{b}+(1-\alpha) \mu_{a}
\end{aligned}
$$

Burada $\alpha$, su için 1 ve hava için 0 olarak tanımlanır.

Türbülans modeli olarak, $\mathrm{k}$, türbülans kinetik enerji (Denklem 7) ve $\varepsilon$, yayılma hızı (Denklem 8) çözümünü gerektiren standart k- $\varepsilon$ seçilir.

$$
\begin{aligned}
& \frac{\partial k}{\partial t}+\frac{\left(k u_{j}\right)}{\partial x_{j}}=\frac{\partial}{\partial x_{j}}\left[\left(v+\frac{v_{t}}{\sigma_{k}}\right) \frac{\partial k}{\partial x_{j}}\right]+p_{k}-\varepsilon \\
& \frac{\partial \varepsilon}{\partial t}+\frac{\partial\left(\varepsilon u_{j}\right)}{\partial x_{j}}=\frac{\partial}{\partial x_{j}}\left[\left(v+\frac{v_{t}}{\sigma_{\varepsilon}}\right) \frac{\partial \varepsilon}{\partial x_{j}}\right]+C_{\varepsilon 1} P_{K} \frac{\varepsilon}{k}-C_{\varepsilon 2} \frac{\varepsilon^{2}}{k}
\end{aligned}
$$

$\mathrm{P}_{\mathrm{K}}$, kinetik enerjinin üretimidir. Denklemlerde görülen her katsayı değeri Tablo 2'de verilmiştir.

\section{Tablo 2. Katsayı Değerleri}

\begin{tabular}{|c|c|c|c|c|}
\hline$C_{\varepsilon 1}$ & $C_{\varepsilon 2}$ & $C_{\mu}$ & $\sigma_{k}$ & $\sigma_{\varepsilon}$ \\
\hline 1.44 & 1.92 & 0.09 & 1.0 & 1.3 \\
\hline
\end{tabular}

Tank yanlarında, alt ve üst duvarlarında kayma olmadığı varsayılmıştır. İlgili denklemler, tüm durumlar için 0.01 saniyelik zaman adımı için çözülmüştür. Javanshir ve arkadaşlarının (2012) çalışması başlangıçta referans olarak takip edilmiş, model teori (White, 2011) ile doğrulanmış ve daha sonra sıvının çalkalanmasını azaltmak için paralel ve tank alt yüzeyine açılı olan bölmeler kullanılmıştır.

\subsubsection{Doğrusal Hızlanma}

Başlangıçta tank hareketsiz tutulur ve $4,5 \mathrm{~m} / \mathrm{s}^{2}$ sabit ivmeyle pozitif $(+)$ x yönünde hareket etmeye başlar. S1vı, denge durumundan sapar ve ardından hareket eder ve tankın duvarı ile çarpışır. Bundan sonra su belirli bir açıyla stabil durumdadır.
Teoriye dayanarak, sıvının serbest yüzeyi basınç gradyanına dik olmalıdır ve bu nedenle Denklem 9 [10] 'da verilen aşağı doğru bir açıyla $(\theta)$ eğilir:

$$
\theta=\operatorname{Arctan}\left(\frac{a_{x}}{a_{y}+\vec{g}}\right)
$$

Burada $\vec{g}, a_{x}$ ve $a_{y}$ sırasıyla yerçekimi ivmesi (y yönünde), xyönünde ivme ve son olarak y yönünde ivmedir. Teorik olarak $\theta$, $24.64^{\circ}$ olarak bulunur. $\mathrm{Bu}$ değer, mevcut CFD çalışmasıyla ve Şahin ve Bayraktar'ın [7] çalışması ile doğrulanmış ve Şekil 4'te gösterilmiştir:

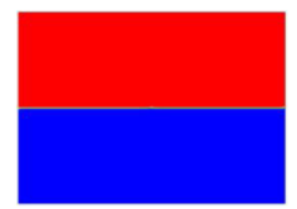

(a)

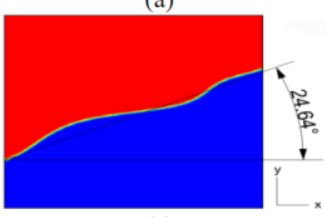

(c)

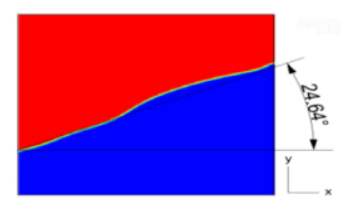

(b)

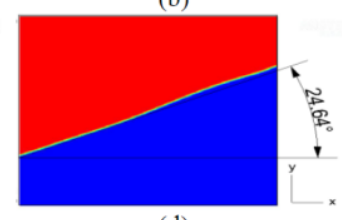

(d)
Şekil 4. a) $t=0$, b) $t=2$ saniye, c) $t=5,5$ saniye, d) $t=10$ saniye boyunca (+) x yönünde $4,5 \mathrm{~m} / \mathrm{s} 2$ doğrusal hızlanma altında perdesiz dikdörtgen bir tankta çalkalanma

\section{Araştırma Sonuçları ve Tartışma}

Şekil 5 'te Tip-1, Tip-2, Tip-3 ve Tip-4 için 6 saniye boyunca oluşan çalkantının hacimsel etkisi verilmiştir. Tanklarda ki $\mathrm{T}=1$ saniyeden $\mathrm{T}=6$ saniyeye kadar çeşitli zamanlardan uyarım altındaki serbest yüzeyin konumu gösterilmektedir. Tip-1 incelendiğinde; başlangıçta akış $+x$ yönüne doğru $4.5 \mathrm{~m} / \mathrm{s} 2$ uyarıldığ için su o yöne hareket etmeye başlar, sağ duvara çarpar ve ardından yükselir. 2. saniyeden sonra uyarımın yönü değişir ve kazanılan enerji ile birlikte yön değiştirerek tankın sol duvarına çarpar, ardından tekrardan uyarımın yönü değişir. Kazandığ enerjiden hem de uyarımdan kaynaklanan eylemsizlikten dolayı devrilip ters dalgalar oluşur. Tip-2,Tip-3 ve Tip-4 için serbest yüzey konumu incelendiğinde akışın $+x$ yönüne doğru uyarıldığında zeminde bulunan perdeden dolayı Tip-1'e kıyasla daha az bir su kütlesinin tank sağ duvarına etki ettiği görülmektedir. $\mathrm{T}=6$ saniye sonunda ters dalgaların oluşumu neredeyse engellenmiştir. Tip-2, Tip-3 ve Tip-4 kendi aralarından kıyaslandığında $\mathrm{T}=1$ anında yan duvarlara konumlanan açılı perdelerin hareketlenen su kütlesini belirli bir hacimde sabit tutmaya zorladığı görülmektedir. $30^{\circ}$ açıya sahip Tip-4; Tip-2 ve Tip-3 ile karşılaştırıldığında, su kütlesinin hareketini sönümlediği açıktır.

Şekil 6'da Tip-1, Tip-5, Tip-6 ve Tip-7 için 6 saniye boyunca oluşan çalkantının hacimsel etkisi verilmiştir. Şekil incelendiğinde hareketlenen su kütlesinin zemine yerleştirilen çift perde ile çalkantısının bir kısmının sönümlendiği ve yükselmesinin engellendiği görülmektedir. Tip-5 için $+x$ ve $-x$ uyarılmaları neticesinde oluşturulan çalkantı ile zamanla sıvı içerisinde hava kabarcıkları oluşmaktadır. Bu durum tank duvarlarına etki eden sıvı darbelerinin tepe basınçlarını etkileyerek basınç değişimlerine neden olur (Kim, 2007). 


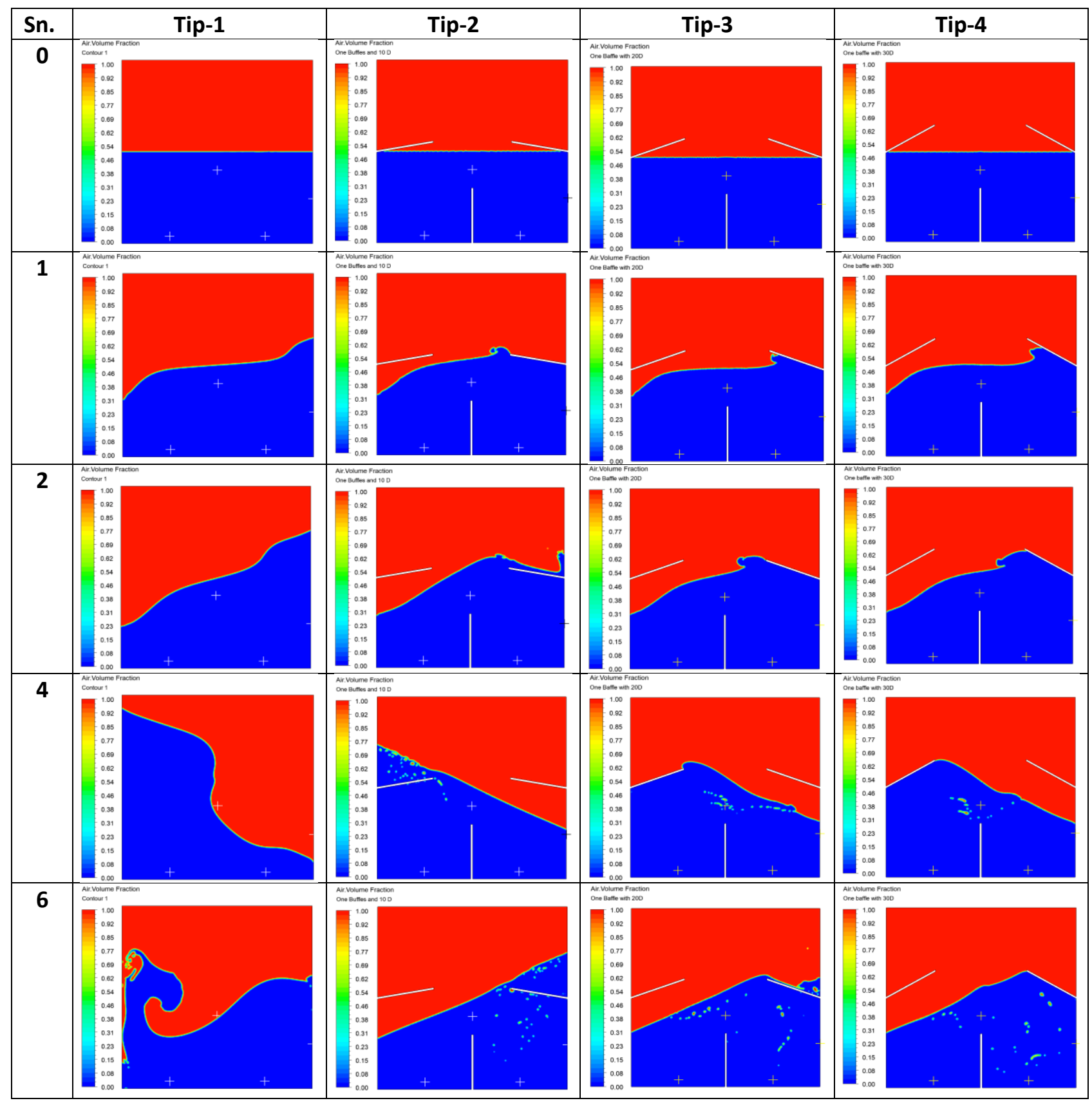

Şekil 5. $10^{\circ}, 20^{\circ}$ ve $30^{\circ}$ zeminde tek perdeli tank yapılarının çalkalanma etkileri 


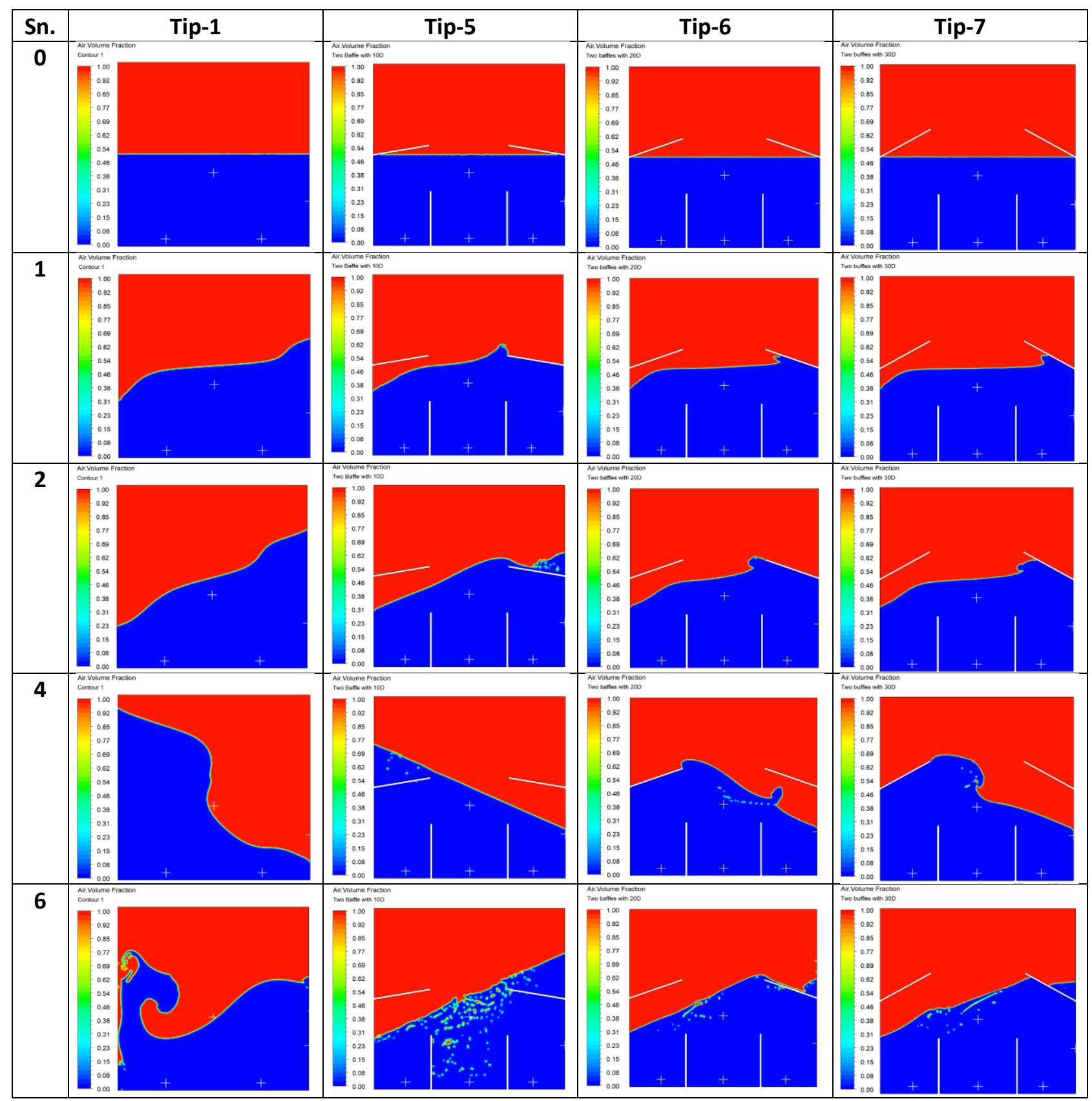

Sekil 6. $10^{\circ}, 20^{\circ}$ ve $30^{\circ}$ zeminde çift perdeli tank yapılarının çalkalanma etkileri

Çalkantı etkilerini görebilmek için Tip-1, Tip-2, Tip-3 ve Tip-4 tank yapılarının Şekil 7'de gösterilen 4 noktadan dinamik basınç değerleri elde edilerek karşıllaştırmalar yapılmıștır.

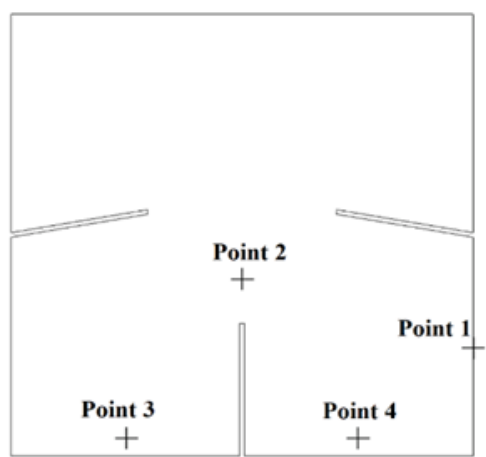

\section{Şekil 7. Tip-1, Tip-2, Tip-3 ve Tip-4 için basınç ölçüm noktalart}

Karşılaştırma noktaları tank yan yüzeyi (Point 1), sıvı serbest yüzeyi (Point 2) ve perdeler arası taban yüzeyi (Point 3 ve Point 4) olarak belirlenmiştir. Bu noktalar perde bölmelerin etkisini görebilmek için belirlenen noktalardır.

Şekil 8' de birinci nokta (Point 1) için 6 saniye boyunca elde edilen dinamik basınç değerleri verilmiştir. Buna göre perdesiz Tip-1 tank yapısının en yüksek basınç değerine 4-5 saniye arasında sahip olduğu görülmektedir. En düşük basınç değeri 20 derece açılı Tip-3'de oluşmuștur. Tip-4'ün Tip-3'den daha düşük bir basınç değeri olması beklenirken, aksine daha yüksek bir basınç değeri ölçülmüştür. Bunun nedeni ise 30 derece açılı perde üzerinde çalkantı sonucu kalan su kütlesinin varlığıdır. 


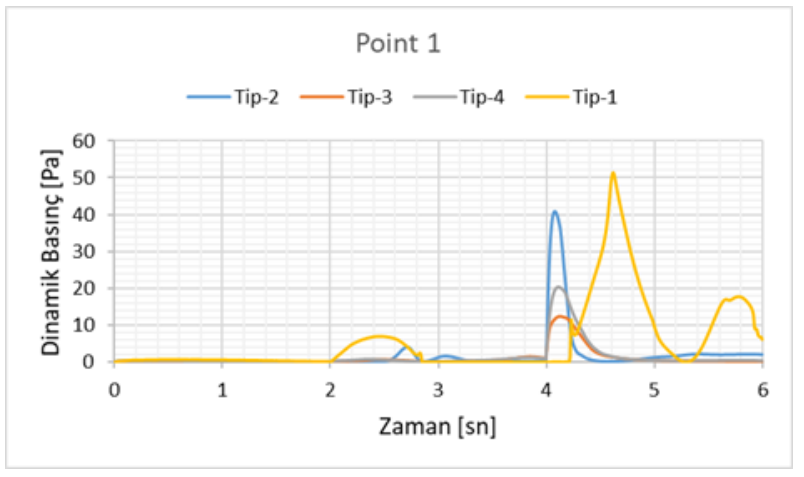

Şekil 8. Birinci noktadan (Point 1) ölçülen dinamik basınç dĕ̌erlerinin zamana bă̆lı değişimi

Şekil 9' da ikinci nokta (Point 2) için 6 saniye boyunca elde edilen dinamik basınç değerleri verilmiştir. Grafik incelendiğinde iki noktasındaki en yüksek basınç değerinin 10 dereceli Tip-2 tank yapısında olduğu görülmektedir. Tip-1 tank yapısının en düşük basınç değerine sahip olmasının nedeni Şekil 5'te de görüldüğü gibi T=4 anında 2 noktasına her hangi bir sıvı teması olmadığı sol duvardan gelen dalganın altında kaldığı görülmektedir. Açıkça görülmektedir ki 20 derece açılı Tip- 3 tank yapısında ölçülen basınç değeri Tip-2 ve Tip-4'ten daha düşüktür. Buna neden olarak 4. saniyeden önce sol duvardan gelen dalganın zemin perdesi tarafından enerjisinin sönümlenmesi ve daha sonra 20 derecelik perdenin akışkanı belirli hacimde durmaya zorlaması gösterilebilir.

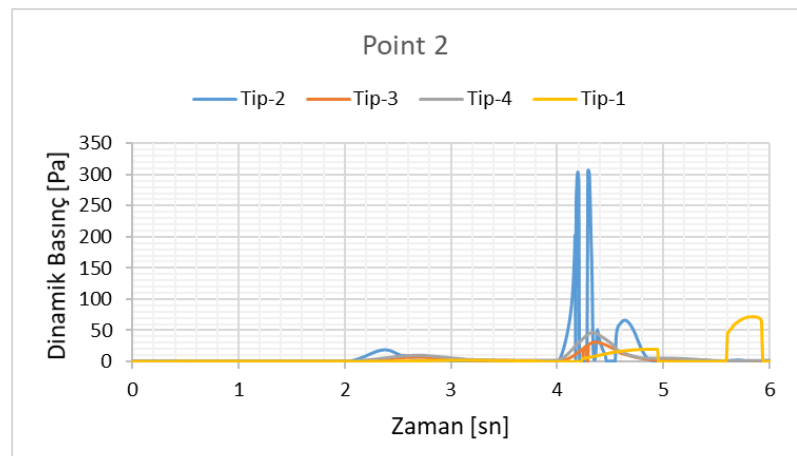

Şekil 9. Íkinci noktadan (Point 2) ölçülen dinamik basınç değerlerinin zamana bağlı değişimi

Şekil 10' da üçüncü nokta (Point 3) için 6 saniye boyunca elde edilen dinamik basınç değerleri verilmiştir. Grafik incelendiğinde 3 noktasından alınan basınç değerlerinin 0-4 saniye arasında ortalama dinamik basınç değeri en düşük Tip-2 tank yapısıdır. Periyodik uyarımlar sonucunda ani ters dalgaların oluşturduğu dinamik basıncı daha iyi sönümlediği ve su kütlesinin engellediğini görülmektedir.

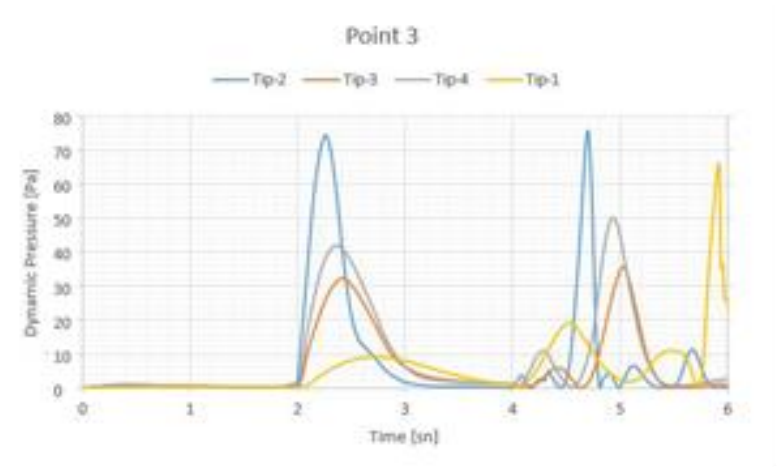

Şekil 10. Üçüncü noktadan (Point 3) ölçülen dinamik basınç değerlerinin zamana bă̆gl de ğişimi

Şekil 11' de dördüncü nokta (Point 4) için 6 saniye boyunca elde edilen dinamik basınç değerleri verilmiştir. 0-6 saniye zaman aralığında çalkantı sonucu oluşan dinamik basınç değerinin en düşük Tip-3'de olduğu görülmektedir.

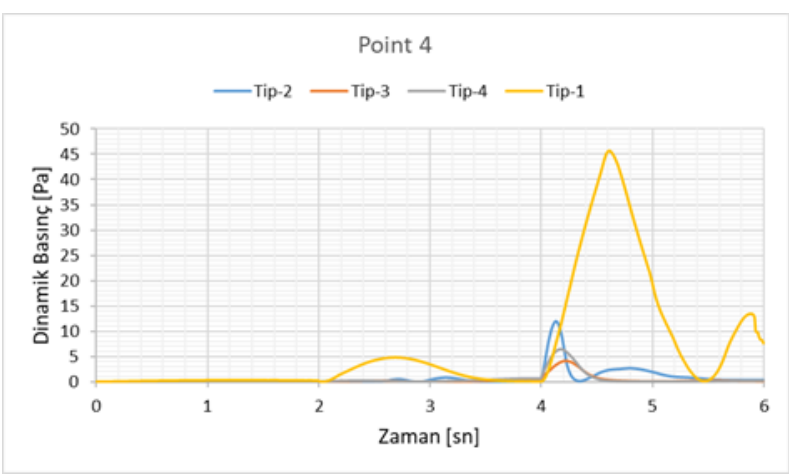

Şekil 11. Dördüncü noktadan (Point 4) ölçülen dinamik basınç değerlerinin zamana bă̆lı değişimi

Çalkantı etkilerini görebilmek için Tip-1, Tip-5, Tip-6 ve Tip-7 tank yapılarının Şekil 12'de gösterilen 5 noktadan dinamik basınç değerleri elde edilerek karşılaştırmalar yapılmıştır. Karşılaştırma noktaları tank yan yüzeyi (Point 1), sıv1 serbest yüzeyi (Point 2) ve perdeler arası taban yüzeyi (Point 3, Point 4, Point 5) olarak belirlenmiştir. Bu noktalar perde bölmelerin etkisini görebilmek için belirlenen noktalardir.

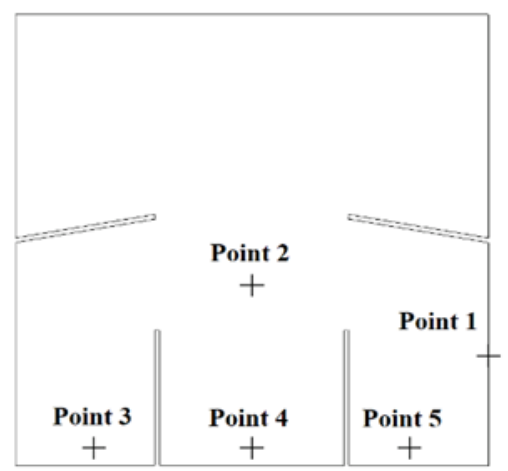

Şekil 12. Tip-1 Tip-5, Tip-6 ve Tip-7 için Basınç Ölçüm Noktalart 
Şekil 12'de belirlenen noktalar için zamana bağlı dinamik basınç değişim grafikleri sırasıyla Şekil 13'te Point 1, Şekil 14 'te Point 2, Şekil 15'te Point 3, Şekil 16'da Point 4 ve Şekil 17 'de Point 5 için gösterilmektedir. $+x$ yönünden $-x$ yönüne geri uyarımın verildiği çalkantının oluşmaya başladığı ikinci saniye sonrası perdesiz tank Tip-1 de dinamik basınç farkı bütün noktalarda oluşmuştur. Bu durum zemine çift perde uygulaması olan diğer modellerde bir sonraki uyarım zamanı olan dördüncü saniyeye taşınmıştır. Her bir nokta için şekiller incelendiğinde tank zemininde çift perde kullanımının dinamik basınç farkını düşürdüğü açıkça görülmektedir. Ayrıca genel olarak basınç dalgasının 4-6. sn aralığında daha etkin olarak karşımıza çıkmaktadır. Şekil 15'te üçüncü noktadan (Point 3) elde edilen basınç dalgalanmasında diğer noktalardan ölçülen basınç değerlerine göre farklılık göstermektedir. Bu durum Tip5 tank yapısında düşük perde açısı nedeniyle dalgalanma sonucu perde üst yüzeylerine ulaşmasından kaynaklanmaktadır.

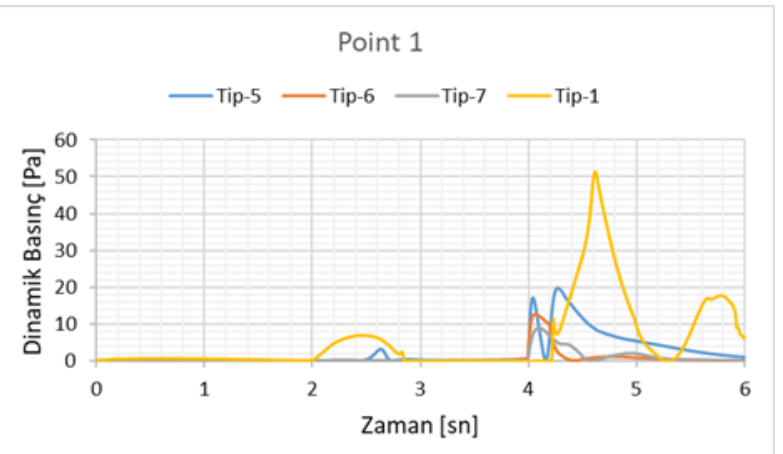

Şekil 13. Birinci noktadan (Point 1) ölçülen dinamik basınç değerlerinin zamana bağlı değişimi

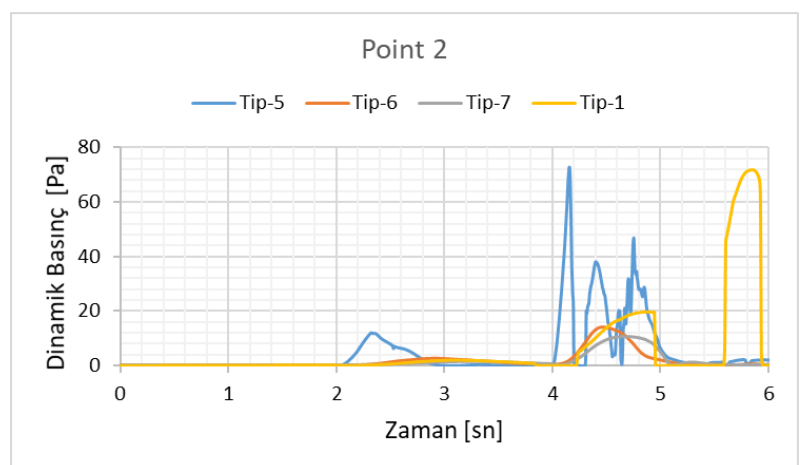

Şekil 14. İkinci noktadan (Point 2) ölçülen dinamik basınç değerlerinin zamana bağlı değişimi

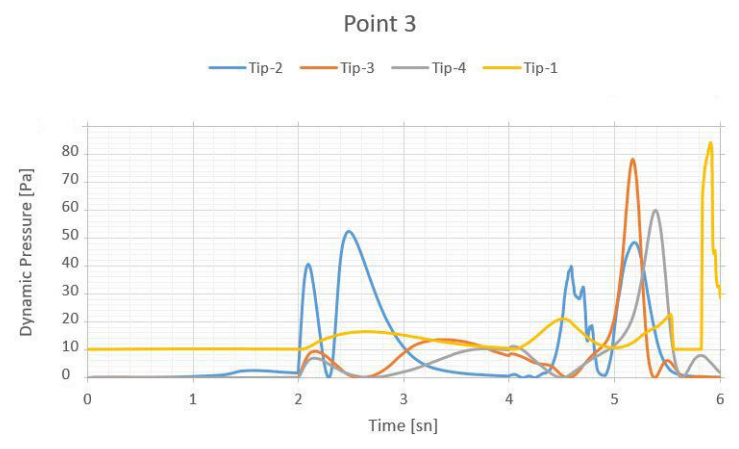

Şekil 15. Üçüncü noktadan (Point 3) ölçülen dinamik basınç değerlerinin zamana bă̆ll değişimi

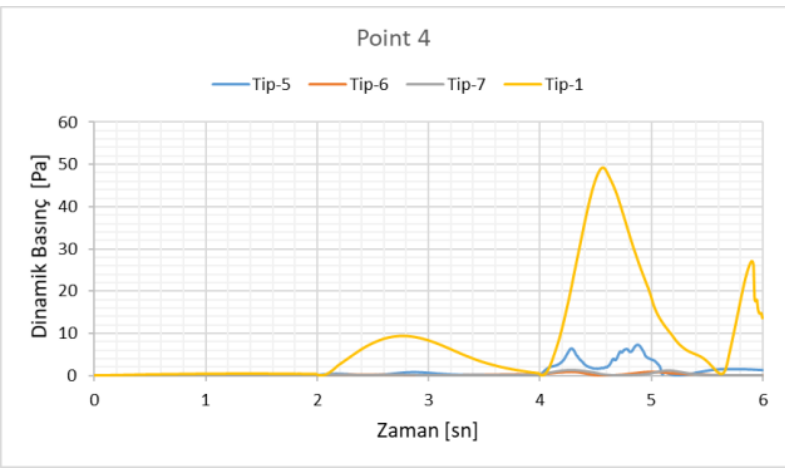

Şekil 16. Dördüncü noktadan (Point 4) ölçülen dinamik basınç değerlerinin zamana bağlı değişimi

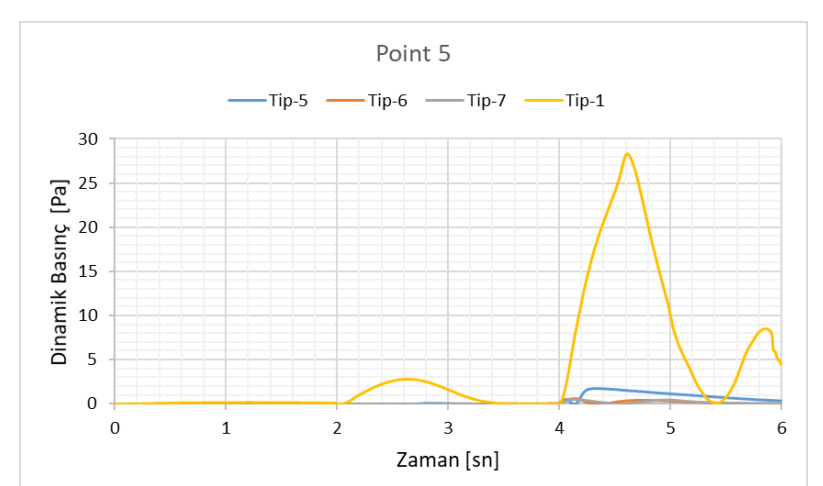

Şekil 17. Beşinci noktadan (Point 5) ölçülen dinamik basınç değerlerinin zamana bağlı değişimi

\section{Sonuç}

$\mathrm{Bu}$ çalışmada, zamana bağlı öteleme hareketi ile iki boyutlu (2B) kaplarda ve yakıt tanklarında sıvı çalkalanmasını simüle edebilen bir hesaplama modeli geliştirilmiştir. Sıvı-gaz ara yüzünün deformasyonu, sıvı hacim (VOF) yöntemi kullanılarak modellenmiştir. Mevcut HAD çalışmasında, aynı koşullar altında yedi tip (Tip-1, Tip-2, Tip-3, Tip-4, Tip-5, Tip6 ve Tip-7) tank analiz edilmiştir. Hesaplama sonuçları, yukarı açılı perdelerin perdesiz tiplere göre sıvı çalkantı genliğini azalttığını göstermektedir. Perdeler, sıvının tank duvarlarına doğru yükselmesini engellemekte ve bu nedenle yapısal elemanların ömrünü kısaltan çalkalanma etkilerini azaltacağı sonucuna varılmaktadır.

Farklı bölme konfigürasyonlarının çalkantı yükleri üzerindeki etkileri, kaplara bölme perdelerinin yerleştirilmesinin çalkantı dalgalarının istenmeyen sonuçlarını önemli ölçüde azaltabileceği dinamik basınç değerlerinin düşürülmesiyle açıktır. Ayrıca, perde bölmelerin kullanımı, yalnızca tank duvarına etki eden çalkantı genliğini ve dinamik darbe basınçlarını önemli ölçüde azaltmakla kalmaz, aynı zamanda serbest yüzey yükselme değerini de değiştirir.

Bu nedenle VOF analiz metodu, taşıyıcı tankerler, gemiler, yakıt tankları ve araç üzerinde istenmeyen kuvvetlere neden olabilecek dalgalanma etkilerini azaltmak için sıv1 tanklarındaki dâhili perdelerin tasarımında ve optimizasyonunda kullanılabilir. 


\section{Kaynakça}

Hu Z.Q., Wang S.Y., Chen G., Chai S.H. (2017). The effects of LNG-tank sloshing on the global motions of FLNG system. International Journal of Naval Architecture and Ocean Engineering, Vol. 9(1), 114-125, doi: 10.1016/j.ijnaoe.2016.09.007.

Javanshir A., Elahi R., Passandideh-Fard M. (2012). Numerical simulation of liquid sloshing in a container with baffles. 12th Iran. Aerosp. Soc. Conf., 27(1), 54-61, doi: 10.3969/j.issn1000-4874.2012.01.008.

Kim Y. (2007). Experimental and Numerical Analyses of Sloshing Flows. Journal of Engineering Mathematics, 58, 191-210, doi.org/10.1007/s10665-006-9124-42007.

Klatte J., Darkow N., Gajdacz R., Goek S. (2020). Sloshing and pressurization tests for membrane tank: Tests, validation and models. Acta Astronaut., Vol. 175, No. May, 338-348, doi: 10.1016/j.actaastro.2020.05.036.

Nema P.K. (2014). Computational study of sloshing behavior in 3 -D rectangular tank with and without baffle under Seismic Excitation. MTech thesis, 212, 61.

Rudman M. \& Cleary, P. W. (2009). Modelling sloshing in LNG tanks. Seventh Int. Conf. CFD Miner. Process Ind., no. December, pp. 1-6.

Sahin, G. \& Bayraktar, S. (2015). Flow Visualization of Sloshing in an Accelerated Two-Dimensional Rectangular Tank. International Journal of Engineering Technologies IJET, 1 (3), 106-112. DOI: 10.19072/ijet.105725

Sanapala V.S., Rajkumar M., Velusamy K., Patnaik B.S.V. (2018). Numerical simulation of parametric liquid sloshing in a horizontally baffled rectangular container. Journal of Fluids and Structures. vol. 76, pp. 229-250, doi: 10.1016/j.jfluidstructs.2017.10.001.

Thiagarajan K.P., Rakshit D., Repalle N. (2011). The airwater sloshing problem: Fundamental analysis and parametric studies on excitation and fill levels. Ocean Engineering, vol. 38, no. 2-3, pp. 498-508, doi: 10.1016/j.oceaneng.2010.11.019.

Wang J. D., Lo S. H., Zhou D. (2013). Sloshing of liquid in rigid cylindrical container with multiple rigid annular baffles: Lateral excitations. J. Fluids Struct., vol. 42, pp. 421-436, doi: 10.1016/j.jfluidstructs.2013.07.005.

White F. M. (2011) Fluid Mechanics, 5th Edition. McGrawHill. 